\title{
Towards a Strengths-Based Personal Informatics Framework for Transformative Tourism Experiences: A Phenomenological Study on Serious Leisure Practitioners
}

\author{
C. K. Bruce Wan ${ }^{1(\bowtie)}$ (D), Cees J. P. M. de Bont ${ }^{2}$, Paul Hekkert ${ }^{3}$, \\ and Kenny K. N. Chow ${ }^{1}$ \\ ${ }^{1}$ School of Design, The Hong Kong Polytechnic University, Hung Hom, \\ Kowloon, Hong Kong \\ \{bruce.wan, ka.nin.chow\}@polyu.edu.hk \\ 2 Loughborough Design School, Loughborough University, \\ Leicestershire LE11 3TU, UK \\ c.j.de-bont@lboro.ac.uk \\ ${ }^{3}$ Faculty of Industrial Design Engineering, TU Delft, Delft, The Netherlands \\ P.P.M.Hekkert@tudelft.nl
}

\begin{abstract}
Personal technology plays an integral role in shaping people's quality of life which includes leisure and tourism experiences. A number of personal informatics tools can support people in performing their activities by collecting biometric and environmental data; however, little is known regarding the use of psychological data to enrich leisure and tourism experiences. To address this research gap, this study aims to propose a conceptual framework that fosters memorable and meaningful leisure experiences (MMEs) based on theories from serious leisure and positive psychology. In particular, this study probes into the MMEs of serious leisure practitioners who put their efforts and resources into pursuing intrinsically rewarding leisure activities. Excelling at these activities, which may draw upon participants' character strengths, yields sustained fulfillment which fosters personal transformation. The idiosyncratic nature of MMEs demands a phenomenological inquiry that involves in-depth interviews concerning the character strengths used and their development trajectories. Using theory triangulation from both positive psychology and serious leisure allows researchers to gain a holistic view of participants' well-being. Character strengths were found to be the integral factors that contribute to MMEs at different stages of leisure activities. The result identified three aspects of strengths used: strengths well spent, reflection and introspection, and anticipation of the future self, which informs the development of a strengths-based personal informatics framework for leisure and tourism.
\end{abstract}

Keywords: Positive psychology $\cdot$ Character strengths $\cdot$ Serious leisure $\cdot$ Meaningful experience $\cdot$ Conceptual framework $\cdot$ Personal informatics 


\section{Introduction}

Technology plays an integral role in supporting the tourism experience. Recent information and communication technology innovation highlights include the emergence of smart tourism, which is characterized by the widespread adoption of personal technologies, big data, and networked devices in tourism settings. Future development may offer travelers new social and experiential dimensions by personalizing the provision of memorable and meaningful experiences (MMEs) [1] that are personally significant [2]. More importantly, the attainment of these goals requires technology that is specifically designed and strategically implemented [3]. Compared to mundane experiences, MMEs are vivid and explicit autobiographical memories that arise from exquisite, remarkable, and valuable events characterized by high emotional involvement and frequent rehearsal [4]. Besides tourism activities, serious leisure [5] can be the source of MMEs because practicing serious leisure often involves one's commitment and self-development. This study investigates how people's character strength and serious leisure activities contribute to MMEs, then proposes a conceptual framework for technology-mediated experience that could support people to gain MMEs in their leisure journeys.

\section{Literature Review}

\subsection{MMEs Through the Lens of Positive Psychology and Serious Leisure}

Positive psychology such as character strengths has been recognized as the personality traits that contribute to people's meaningful lives [6]. The values in action (VIA) classification of character strengths [7] proposes six main virtues and 24 related character strengths (see Table 1). Character strengths are conceptualized as a preexisting capacity for a particular way of behaving, thinking, or feeling that is authentic and energizing to the user and enable optimal functioning, development and performance. They are behaviorally based unique personality traits; each individual is affiliated with their own bundle of strengths (top five) known as signature character strengths. The strength-based approach suggests that recognizing and making good use of one's inherent character strengths are the channels through which people generate positive experiences, find meaning and ultimately flourish [8]. One of the most reliable ways to identify MMEs is through the pursuit of intentional activities that match one's personal character strengths [9]. These activities should be intrinsically rewarding and interesting and, when engaged in them, individuals may feel a sense of purpose, curiosity and fulfilment [10].

Serious leisure (SL) [5] can be the activity which allows people to develop their character strengths [11]. SL is regarded as the systematic pursuit of an amateur, hobbyist or volunteer activity sufficiently substantial, interesting and fulfilling for a participant to find a (leisure) career there in acquiring and expressing a combination of its special skills, knowledge and experience [5]. SL delineates six characteristics which describe its inherent quality: 1 . the need to persevere with the activity; 2 . possibility to develop a leisure career; 3 . the need to put substantial effort into gaining skills and 
knowledge; 4. unique ethos and community; 5. identification with the pursuit; and 6. gaining valuable outcomes and benefits. Despite practitioners often being confronted with difficulties and challenges in their pursuit, serious leisure activities are intrinsically rewarding and interesting, and when engaged in them, individuals may feel a deep sense of purpose and fulfillment leading to self-transformation [12]. This study uses the two bodies of knowledge to probe into how people gain MMEs through their character strengths development in their serious leisure pursuits.

Only recently MME has gained traction in tourism research for its enduring wellbeing benefits [13] which lead to self-transformation [14]. Also, eTourism study [15] has called for a transformative research agenda that incorporates transparency, plurality and creativity to foster sustained well-being to be developed for the tourism industry.

Table 1. Values in action classification of character strengths and virtues [7]

\begin{tabular}{l|l|l|l}
\hline Virtues & Character strengths & Virtues & Character strengths \\
\hline Wisdom & $\begin{array}{l}\text { Creativity, Curiosity, Judgment, } \\
\text { Love of learning, Perspective }\end{array}$ & Transcendence & $\begin{array}{l}\text { Appreciation of beauty } \\
\text { \& excellence, Gratitude, } \\
\text { Hope, Humor, } \\
\text { Spirituality }\end{array}$ \\
\hline Courage & $\begin{array}{l}\text { Bravery, Perseverance, } \\
\text { Honesty, Zest }\end{array}$ & Temperance & $\begin{array}{l}\text { Forgiveness, Humility, } \\
\text { Prudence, Self-regulation }\end{array}$ \\
\hline Humanity & $\begin{array}{l}\text { Love, Kindness, } \\
\text { Social intelligence }\end{array}$ & $\begin{array}{l}\text { Jeamwork, Fairness, } \\
\text { Leadership }\end{array}$ \\
\hline
\end{tabular}

\subsection{Potential of Using Technology to Support MMEs}

Personal technology plays an integral role in shaping people's quality of life which includes leisure and tourism experiences. It refers to a class of tools that help people to collect personally relevant information for the purpose of self-monitoring and selfreflection [16]. Tourism researchers [17] have suggested that the ubiquitous nature of technology gives it the potential to create MMEs via individual empowerment [3]. For instance, wearable devices support people to perform their activities by capturing and analyzing biometric, environmental, and social data. However, little is known on using psychological data, such as character strengths, to enrich leisure and tourism experiences. Wan and his colleagues [18] demonstrated a strengths-based digital diary which allowed people to journal and savor memorable and meaningful tourism moments with photos and texts provided by users. The journal platform supports users to reveal meaning by making implicit psychological dimensions of MMEs explicit. As such, the incorporation of psychological dimensions in personal informatics could foster transformative tourism experiences. The goal of this study was to propose a conceptual framework that incorporates character strengths into informatics that may foster MMEs in leisure and tourism. Especially, this study explored how the system of smart things can be used as a mediator to nurture people's character strengths. This study addressed the following questions: 
RQ1: How do individuals draw upon their character strengths in their sustained pursuits of leisure activities to generate memorable and meaningful experiences during their travels?

RQ2: What opportunities are there for personal informatics to foster MMEs using the themes identified in RQ1?

\section{Research Methodologies and Methods}

This study acknowledged that individual sense-making and experience of SL are highly contextual and influenced by the complex and ever-changing social phenomena encountered [19]. Using an idiographic approach, the research objective was to determine how character strengths contribute to the generation of MMEs through the pursuit of SL activity in the context of tourism. The data collection involved a questionnaire and one-on-one thematic in-depth interviews. The questionnaire introduced character strengths literacy to the participants so that they could recognize their signature character strengths through self-nomination [20]. The in-depth interviews, on the other hand, invited the participants to introduce their serious leisure activities and explain why their activities are attractive, engaging, and meaningful to them. Also, the participants were invited to associate their character strengths with key memorable and meaningful moments of their leisure practices. Interpretative phenomenological analysis (IPA) [21] was performed to identify the participants' meaning and sense-making from their personal standpoint at the idiographic level. The analysis drew upon the fundamental principles of phenomenology and hermeneutics and captured the participants' memorable and meaningful SL experiences through their use of character strengths as personal resources. In a hermeneutic phenomenology-informed framework, researchers must explore, describe, interpret, and identify the means by which participants make sense of their own experiences [21]. The IPA process defines five interconnected stages, from transcription to theme generation, based on the recorded interviews. In this study, stage one consisted of becoming familiar with the transcript to gain a keen sense of the SL world of the participants. Then, based on the transcripts, we generated codes and made notes on our observations and reflections about items that may have potential significance. In stage three, these codes and notes were transformed into emerging themes and were connected with positive psychology conceptualizations. Then relationships and patterns among the identified emerging themes were identified. Lastly, based on representative interview data, we generated case narratives featuring these themes. The result supported the development of a conceptual framework for a strengths-based informatics system.

\subsection{Sampling, Data Collection, and Analysis}

This exploratory study considered the sample to represent the breadth of the SL landscape. This study used non-probability and purposive samples and considered that SL can be practiced regardless of age, educational background, household composition, or profession. Although people's sense-making may have cultural influence, this study 
examined the process of sense-making by making their character strengths explicit. Therefore, the participants deemed suitable for this study had to fulfill two criteria: they were to be SL practitioners in any of the domains identified by Stebbins and they must have practiced their SL, either partially or entirely, on one or more of their journeys. The participants were recruited through social networks using convenience and snowball sampling methods to connect with different SL communities. Seven participants were involved in this study, who engaged in different SL genres and demonstrated varying degrees of commitment. All participants were of Chinese ethnicity and lived and worked in Hong Kong at the time of the interview. Each interview lasted for around $90 \mathrm{~min}$, and the interview sessions were audio-recorded, translated, and then transcribed into verbatim English transcripts for further data analysis. The following are questions from the interview protocol:

"The assessment showed that these are your signature strengths. Do you think that these strengths describe you well?"

"Can you share with me what made you devoted to your serious leisure?"

"What are your most memorable and meaningful experiences? Do you see that any of your character strengths take part in these experiences?"

"What do you enjoy most in your pursuit?"

"What motivates you in your serious leisure activity?"

"Why is that experience valuable to you? Can you see any of your character strengths in that experience?"

"What are the turning points in your pursuit? How did you overcome these challenges? How does it relate to your character strengths?"

"What did you learn from that experience?"

"Do you think that your serious leisure activity made you a better person? How?"

Table 2 lists the participants' backgrounds, SL activities, years of experience and personal statements regarding their pursuits.

Table 2. List of participants, activities, and signature strengths regarding their serious leisure pursuits

\begin{tabular}{l|l|l|l|l}
\hline Pseudonym $^{\mathrm{a}}$ & Domain & Activity & Exp. (year) & Signature strengths $^{\mathrm{b}}$ \\
\hline Emily & $\begin{array}{l}\text { Natural } \\
\text { science }\end{array}$ & WWOOF $^{\mathrm{c}}$ & 1 & $\begin{array}{l}\text { Zest, Humour, Kindness, } \\
\text { Love of learning, } \\
\text { Curiosity }\end{array}$ \\
\hline Kelly & Entertainment & Swing dance & 7 & $\begin{array}{l}\text { Social intelligence, } \\
\text { Kindness, Zest, Love of } \\
\text { learning, Curiosity }\end{array}$ \\
\hline Sofia & Art \& Culture & $\begin{array}{l}\text { Documentary } \\
\text { photography }\end{array}$ & 10 & $\begin{array}{l}\text { Creativity, Love of } \\
\text { learning, Judgment, } \\
\text { Appreciation of Beauty } \\
\text { and Excellence, Curiosity }\end{array}$ \\
\hline Shane & Sport & $\begin{array}{l}\text { Rock } \\
\text { climbing }\end{array}$ & 8 & $\begin{array}{l}\text { Creativity, Judgment, } \\
\text { Prudence, Honesty, Self- } \\
\text { regulation }\end{array}$ \\
\hline
\end{tabular}

(continued) 
Table 2. (continued)

\begin{tabular}{l|l|l|l|l}
\hline Pseudonym $^{\mathrm{a}}$ & Domain & Activity & Exp. (year) & Signature strengths \\
\hline Evan & Sport & Dinghy racing & 13 & $\begin{array}{l}\text { Zest, Perseverance, } \\
\text { Bravery, Perspective, } \\
\text { Judgment }\end{array}$ \\
\hline Orion & Spirituality & $\begin{array}{l}\text { Theravada } \\
\text { meditation }\end{array}$ & 7 & $\begin{array}{l}\text { Honesty, Hope, } \\
\text { Forgiveness, Humility, } \\
\text { Perspective }\end{array}$ \\
\hline Andy & Volunteer & $\begin{array}{l}\text { Volunteer on } \\
\text { education } \\
\text { project }\end{array}$ & 7 & $\begin{array}{l}\text { Judgment, Perspective, } \\
\text { Kindness, Teamwork, } \\
\text { Gratitude }\end{array}$ \\
\hline
\end{tabular}

${ }^{a}$ Name and details of the participants are changed to preserve confidentiality.

${ }^{\mathrm{b}}$ Statements were formulated based on the data collected in the interviews.

${ }^{\mathrm{c}}$ WWOOF refers to Worldwide Opportunities on Organic Farms, a network of organizations that facilitate overseas work placements on organic farming.

\section{Results}

\subsection{Different Roles of Character Strengths in the Generation of MMEs}

In response to RQ1, three core themes and six sub-themes were identified (Table 3). The results show that MMEs are multidimensional. As a measure of their credibility, all themes were supported by at least five participants [21]. Below, each theme is elaborated upon with a detailed description, and examples in the participants' own words are provided along with the researchers' interpretations. Discussions are offered at the end of each theme.

Theme 1: Strengths Well Spent. This refers to the purposeful use of one's character strengths in the creation of specific and distinctive experiences during one's journey. The experience must be specific enough for the person to have a clear goal they wished to achieve and character strengths are purposefully used for the person to achieve a desirable outcome, even though the final outcome may not fulfill the initial expectation. Two sub-themes were identified: on producing positive experiences (i.e., seeking sustained fulfillment) or on problem-solving (i.e., pain avoidance). Emily's story helped to illustrate how character strengths were well spent for realizing sustained fulfillment. Since Emily loves to connect with nature, WWOOFing trips allow her to dedicate herself to this connection. To make her experience more intellectual, she once took a butterfly guidebook with her:

I bought a butterfly field guidebook to take with me so I could learn how to distinguish between various species of butterfly from the tiny differences I observed... sizes and patterns... I really enjoyed the self-learning process. (Emily)

The excerpt highlights Emily's character strengths (i.e., curiosity and love of learning) used for the purpose of seeking positive experiences (i.e., seeking autonomy and knowledge). In contrast, Shane's experience is characterized by solving immediate 
problems. Shane connects creativity with her experience at the rock-climbing site in this way:

You need to be creative in everyday life situations because you must do things with very limited resources at your disposal. For example, using the same piece of cloth as a dress one day and as a tablecloth another. (Shane)

Lastly, character strengths are used for both problem solving and sustained fulfillment in the context of competition and performance. Evan's dinghy racing showed that bravery, self-control, and perseverance were needed in one of her offshore competitions:

The wind was unexpectedly strong! I really felt in danger when racing in such conditions. I also felt the pressure of being the pilot... For that competition, I required medical treatment every day because my whole body was so tense and overworked... But participating in competitions is what I like in this sport. (Evan)

The experience is comparable to flow, for which a balance of skill and challenge can lead to an optimal experience. Evan's experiences illustrate that character strengths can play a part in people's skill development in the pursuit of excellence. Nevertheless, the participants had divergent attitudes and behaviors toward their pursuits of excellence.

These anecdotes also highlight how one's affect and emotional responses play a role in formulating these MMEs. Furthermore, MMEs are not purely subjective; they are the result of constant interactions between the participant (i.e., strengths, affects, and emotional responses) and his/her surroundings (i.e., other people, objects, the environment). Moreover, these MMEs are significant to the participants, even when their initial goals are not (totally) fulfilled. These goals can be explicit and well-defined, as in Evan's dinghy racing (i.e., be the first past the finish line), or they can be implicit and not clearly defined (or even improvised) as in Shane's story (i.e., creative use of cloth has no limits). To conclude, this theme describes how people draw upon their character strengths to have MMEs.

Theme 2: Reflection and Introspection. This refers to the integration of the MMEs in one's life. These experiences can be either positive or negative and the related character strengths are not always obvious. The experience can emerge from one particular event (as shown in theme 1), an aggregation of multiple events, or as an overall impression of the experience. Through reflection and introspection, individuals try to make sense of these experiences by analyzing and interpreting them as valuable and meaningful in their lives - whether by learning a new aspect of life, gaining perspective on one's life, personal growth, or enriching one's life experience as a whole. Two sub-themes have been identified - savoring positive experiences [22] and reappraising negative experiences [23]. Andy shared an account of a mentally handicapped child who lived in the village where a school construction project was taking place. The child was unable to take care of himself and the villagers mostly ignored him or, at worst, bullied him. He worked in that village for two consecutive years and what he encountered this year was a personal epiphany:

Last year, I found the child annoying because he often disturbed us at the construction site. This year, we have a volunteer who is a mother and a social worker in a special education school. Instead of ignoring him, she welcomed him with open arms and spent time with him. The child 
became happier than ever before, and her kindness was spread throughout the volunteer group. This experience inspired me in many ways: first, love and care are contagious. Second, problems can be solved in positive ways... the child was only seeking love and care. In fact, this is what we are all looking for. (Andy)

Through the savoring of a positive experience, Andy's illumination is rooted in connecting a particular experience with his past experience and with the wider scope of life. This became one of the most profound experiences in his years of volunteer work.

MMEs are not always positive; painful experiences, difficult times, and failure are all common aspects of serious leisure pursuits. Our interviews showed that the participants had managed their negative experiences by finding them to be beneficial and rewarding aspects of their lives. This process is known as the positive reappraisal of negative experiences [23], which helps individuals to transcend negative experiences and to transform them into something meaningful and purpose-filled such that they contribute to personal growth. Orion shared how her chronic illness (i.e., negative experiences), which impeded her further meditation practice, had been transcended into something worthwhile and personally significant.

I felt completely disorientated after my diagnosis. I lost my goal because I was totally devoted to meditation at that time... but my sickness also made me somewhat more positive-minded because I realized that I needed to accept my sickness. I have to get through it with mindfulness and to learn how to build awareness in everyday life. (Orion)

These anecdotes illustrate how remarkable experiences, as a result of character strengths well spent, become meaningful, worthwhile, and purpose-filled by their integration into individuals' life experiences and beliefs. The savoring process focuses on cherishing, enjoying, and relishing positive experiences and elevates the experience of pleasure to a higher order of awareness. It allows people to appreciate their experience as involving something deeper than the immediate personal reactions and sensations. The positive appraisal of negative experiences, on the other hand, transforms an outcome previously perceived as negative into a meaningful and growth-promoting outcome that helps one to build resilience, act positively, and overcome adversity.

Theme 3: Anticipation of Future Self. This refers to the seeking out and planning for experiences that are congruent with the individual's personal interests [24] and that fit into the individual's development trajectory [25]. Here, character strengths also play a role in identifying such experiences. This anticipation allows individuals to pursue activities that foster eudaimonic growth. Two sub-themes were identified: seeking commitment and seeking alternatives. Over the course of our interviews, the participants shared their experiences in their development trajectory. Those with the intention to seek commitment are likely to connect their pursuits with a career path. Kelly shared her experiences of finding her future self in connection with her potential career development:

I wanted to integrate swing dance somehow into my performance and to be a swing dance teacher for college students. Swing dance can help them to build a dynamic social network. (Kelly)

However, Orion reacted to situations differently when attempting to project her future self: 
I need to find an activity that allows me to meditate and develop my awareness. I recently began running, an activity in which I previously had no interest. By integrating self-awareness and setting up small challenges, I was able to better enjoy running. I hope to develop myself as a runner with the same approach and attitude as I did in meditation. (Orion)

In contrast to the other participants, Orion wanted to explore alternative activities in which their personal interests and character strengths are valued. Instead of deepening her commitments, she wanted to broaden their fields of activity and experience new things. This attitude is somewhat echoed in the broaden-and-build theory [25] in which positive emotions allow people to be open to new experiences and, thus, build enduring personal resources by undertaking new challenges. The difference may be that meaning and self-worth, in addition to positive emotions, are motivators for their decisions.

Table 3. Summary of themes and sub-themes

\begin{tabular}{l|l|l}
\hline Theme & Sub-theme & Description \\
\hline $\begin{array}{l}\text { Strengths well } \\
\text { spent }\end{array}$ & $\begin{array}{l}\text { Producing } \\
\text { valuable } \\
\text { experiences }\end{array}$ & $\begin{array}{l}\text { Using signature strengths purposefully in the } \\
\text { production of valuable and significant experiences }\end{array}$ \\
\cline { 2 - 3 } $\begin{array}{l}\text { Solving } \\
\text { immediate } \\
\text { problems }\end{array}$ & Using signature strengths for problem-solving \\
\hline $\begin{array}{l}\text { Reflection and } \\
\text { introspection }\end{array}$ & $\begin{array}{l}\text { Savoring positive } \\
\text { experiences }\end{array}$ & $\begin{array}{l}\text { Reminiscing about good characters, and valuable } \\
\text { and significant experiences as being memorable and } \\
\text { meaningful in one's life }\end{array}$ \\
\cline { 2 - 3 } $\begin{array}{l}\text { Reappraising } \\
\text { negative } \\
\text { experiences }\end{array}$ & $\begin{array}{l}\text { Transforming negative experiences into positive } \\
\text { personal development }\end{array}$ \\
\hline Anticipation of & $\begin{array}{l}\text { Seeking } \\
\text { commitment }\end{array}$ & $\begin{array}{l}\text { Cultivating character strengths to further one's } \\
\text { personal development trajectory }\end{array}$ \\
\cline { 2 - 3 } & $\begin{array}{l}\text { Seeking } \\
\text { alternatives }\end{array}$ & $\begin{array}{l}\text { Identifying other opportunities in which personal } \\
\text { strengths and interests are valued }\end{array}$ \\
\hline
\end{tabular}

\subsection{Towards a Strengths-Based Personal Informatics Framework}

In response to RQ2, this study proposed a strengths-based personal informatics framework (Fig. 1) that supports individuals to generate, appreciate, and pursue MMEs in their leisure and tourism activities based on the themes identified. The framework focuses on personally relevant characters which could facilitate a self-reflection process through breaking down memorable and meaningful experiences, inquiring about the character strengths involved and fostering self-transformation with strengths interventions. The framework is compatible with current studies [3, 18] on digital wellbeing informatics systems. The following provides recommendations for developers to implement strengths-based personal informatics. Above all, building awareness of character strengths should be an important step for strengths-based personal informatics in order to make users familiar with character strengths (e.g., definition and 
characteristics). It can be achieved by introducing users to character strengths literacy, establishing a strength profile, and using character strengths as the system language.

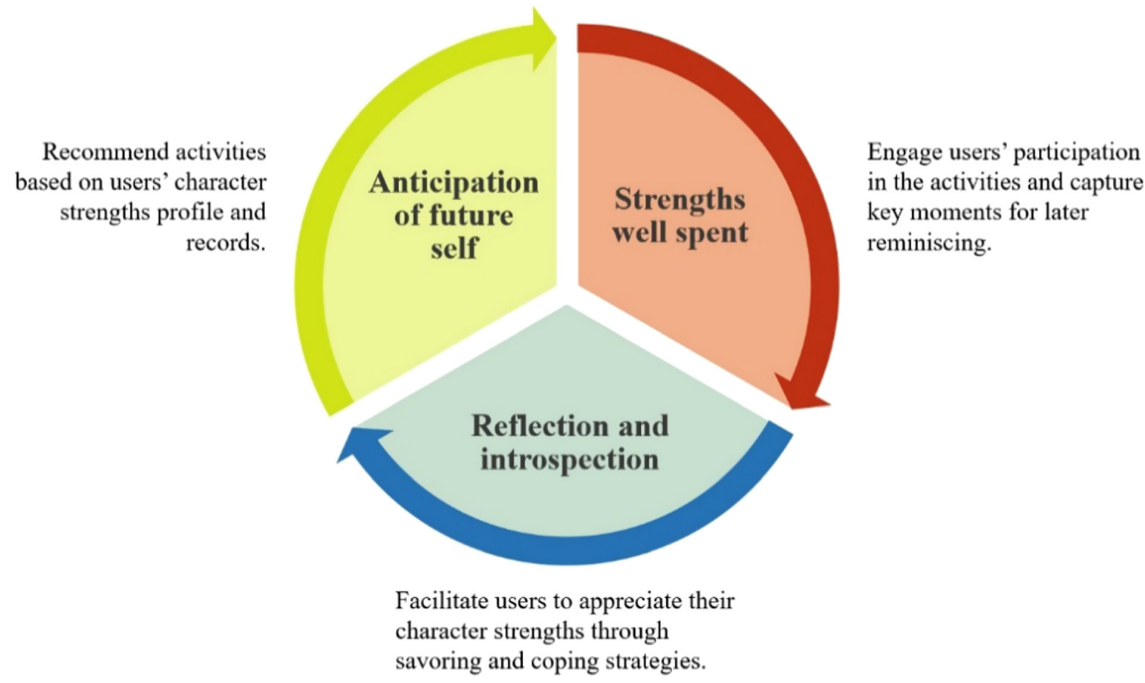

Fig. 1. Conceptual framework for strengths-based personal informatics

Guideline 1. Living in and exploring the present moment. This aspect of informatics systems is to support users to immerse themselves in the present moment and capture the moment for later reminiscing. Technology can take account of the user's character strengths and combined with situation-awareness technologies support users' immersion in their experiences [26]. Technologies may also collect onsite data relevant to the activity for users to savor the moment.

Guideline 2. Appreciating one's character strengths through reflection and introspection. This is probably the easiest way for people to connect their strengths with external stimuli (e.g., people, activities, environments, etc.) and their internal psychological states (e.g., values, goals, feelings). Reflection and introspection can be an effective way to allow users to recognize the character strengths they draw upon in gaining valuable experiences [18]. Reflection allows people to bring unconscious aspects of experience to conscious awareness, and thereby gain self-knowledge.

Guideline 3. Anticipating one's future self with character strengths. Being aware of one's implicit character strengths may also inspire one to cultivate them [27]. Technology may provide strengths-based recommendations to users so that they can broaden their perspectives or deepen their commitment to the activities. The system may facilitate users to generate goals that are valuable and meaningful to them. 


\section{Limitations and Future Research Direction}

This study has a few limitations. First, the idiosyncratic nature of MMEs limited this research by requiring it to start with a small sample size. Future research can consider using a larger sample size and a diverse user group. The proposed framework suggested directions for a developer to incorporate character strengths into an informatics system. Nevertheless, this study demonstrates that character strengths are a necessary but not sufficient condition for generating meaningful experiences. Interview data showed that, in addition to the purposeful use of strengths, the participants garnered meaningful experiences through constant interaction with a complex network of activities, environments, objects, and people. Also, further investigations on managerial and ethical implications are necessary even if the informatics system can support people's wellbeing. After all, the strength-based approach is as yet little explored in tourism studies. More research is needed to incorporate the framework into personal informatics applications.

\section{References}

1. Tussyadiah IP (2017) Technology and behavioral design in tourism. In: Fesenmaier DR, Xiang Z (eds) Design Science in Tourism. TV. Springer, Cham, pp 173-191. https://doi.org/ 10.1007/978-3-319-42773-7_12

2. Neuhofer B, Buhalis D, Ladkin A (2015) Smart technologies for personalized experiences: a case study in the hospitality domain. Electron Mark 25(3):243-254. https://doi.org/10.1007/ s12525-015-0182-1

3. Stankov U, Gretzel U (2021) Digital well-being in the tourism domain: mapping new roles and responsibilities. Inf Technol Tourism 23(1):5-17. https://doi.org/10.1007/s40558-02100197-3

4. Tung VWS, Ritchie JRB (2011) Investigating the memorable experiences of the senior travel market: an examination of the reminiscence bump. J Travel Tour Mark 28:331-343. https:// doi.org/10.1080/10548408.2011.563168

5. Smith JM, Williams A, Mullane F (2014) An introduction. Domestic Abuse, Homicide and Gender. Palgrave Macmillan, London, pp 1-8. https://doi.org/10.1057/9781137307439_1

6. Peterson C, Park N (2012) Character strengths and the life of meaning. In: Wong PTP (ed) The Human Quest for Meaning. Routledge, New York, p 20

7. Peterson C, Seligman MEP (2004) Character Strengths and Virtues: A Handbook and Classification. APA American Psychological Association, Washington

8. Corral-Verdugo V, Tapia-Fonllem C, Ortiz-Valdez A (2015) On the relationship between character strengths and sustainable behavior. Environ Behav 47:877-901

9. Seligman MEP, Steen TA, Park N, Peterson C (2005) Positive psychology progress: empirical validation of interventions. Am Psychol 60(5):410-421

10. Csikszentmihalyi M (1997) Finding Flow: The Psychology of Engagement with Everyday Life. Basic Books, New York

11. Dieser RB, Christenson J (2016) Integrating positive psychology, behavioral activation, and the serious leisure perspective in mental health counseling. Int J Appl Posit Psychol 1:57-68

12. Csikszentmihalyi M, LeFevre J (1989) Optimal experience in work and leisure. J Pers Soc Psychol 56:815-822. https://doi.org/10.1037/0022-3514.56.5.815 
13. Alizadeh A, Filep S (2019) Well-being. In: Tourist Behaviour. Edward Elgar Publishing, pp 347-364

14. Kirillova K, Lehto X, Cai L (2017) What triggers transformative tourism experiences ? Tour Recreat Res 42:498-511. https://doi.org/10.1080/02508281.2017.1342349

15. Gretzel U et al (2020) e-Tourism beyond COVID-19: a call for transformative research. Inf Technol Tourism 22(2):187-203

16. Li I, Dey A, Forlizzi J, et al (2011) Personal informatics and HCI: design, theory, and social implications. In: Proceedings of the 2011 Annual Conference Extended Abstracts on Human Factors in Computing Systems - CHI EA 2011, Vancouver, BC, Canada. ACM Press, p 2417

17. McCabe S, Sharples M, Foster C (2012) Stakeholder engagement in the design of scenarios of technology-enhanced tourism services. Tourism Manag Perspect 4:36-44

18. Wan CKB, de Bont CJPM, Hekkert P, Chow KKN (2021) Finding meaning through travel journaling: a strength-based approach. In: Wörndl W, Koo C, Stienmetz JL (eds) Information and Communication Technologies in Tourism 2021. Springer, Cham, pp 137-149. https:// doi.org/10.1007/978-3-030-65785-7_12

19. Gillespie A, Cornish F (2010) Intersubjectivity: towards a dialogical analysis. J Theory Soc Behav 40:19-46. https://doi.org/10.1111/j.1468-5914.2009.00419.x

20. Niemiec RM (2017) Character Strengths Interventions: A Field Guide for Practitioners. Hogrefe, Boston

21. Smith JA (2011) Evaluating the contribution of interpretative phenomenological analysis. Health Psychol Rev 5:9-27. https://doi.org/10.1080/17437199.2010.510659

22. Bryant FB, Veroff J (2007) Savoring: A New Model of Positive Experience. Lawrence Erlbaum Associates, Mahwah

23. Garland EL, Gaylord SA, Fredrickson BL (2011) Positive reappraisal mediates the stressreductive effects of mindfulness: an upward spiral process. Mindfulness 2:59-67

24. Sheldon KM, Elliot AJ (1999) Goal striving, need satisfaction, and longitudinal well-being: the self-concordance model. J Pers Soc Psychol 76:482

25. Fredrickson BL (2001) The role of positive emotions in positive psychology: the broadenand-build theory of positive emotions. Am Psychol 56(3):218-226

26. Stankov U, Filimonau V, Gretzel U, Vujičić MD (2020) E-mindfulness - the growing importance of facilitating tourists' connections to the present moment. JTF 6:239-245

27. Proctor C, Tweed R, Morris D (2014) The naturally emerging structure of well-being among young adults: "big two" or other framework? J Happiness Stud 16:257-275. https://doi.org/ 10.1007/s10902-014-9507-6

Open Access This chapter is licensed under the terms of the Creative Commons Attribution 4.0 International License (http://creativecommons.org/licenses/by/4.0/), which permits use, sharing, adaptation, distribution and reproduction in any medium or format, as long as you give appropriate credit to the original author(s) and the source, provide a link to the Creative Commons license and indicate if changes were made.

The images or other third party material in this chapter are included in the chapter's Creative Commons license, unless indicated otherwise in a credit line to the material. If material is not included in the chapter's Creative Commons license and your intended use is not permitted by statutory regulation or exceeds the permitted use, you will need to obtain permission directly from the copyright holder.

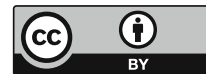

